\title{
Simbologia e hereditariedade na formação de uma Grundgestalt: a primeira das Quatro Canções Op.2 de Berg
}

\author{
Carlos de Lemos Almada (UFRJ, Rio de Janeiro, RJ) \\ calmada@globo.com
}

\begin{abstract}
Resumo: Integrando um amplo projeto de pesquisa que visa elaborar uma metodologia analítica específica para os procedimentos de variação progressiva, o presente estudo examina a possibilidade de existência de, por assim dizer, transmissão hereditária (extraopus) na construção da ideia primordial (ou Grundgestalt) de uma peça musical. Para isso, é analisada a primeira das Quatro Canções op.2, de Alban Berg, cuja Grundgestalt apresenta-se como um complexo formado por várias transformações de elementos-chave extraídos de três obras: Tristão e Isolda de Richard Wagner, a Primeira Sinfonia de Câmara op.9 de Arnold Schoenberg e a Sonata para Piano op.1, do próprio Berg.
\end{abstract}

Palavras-chave: Grundgestalt e variação progressiva; simbologia musical; transmissão extraopus.

\section{Symbology and heredity on the formation of a Grundgestalt: the first of Berg's Four Songs Op.2}

Abstract: As a part of a broad research project that aims at elaborating a specific analytical methodology for the procedures of developing variation, the present study examines the possibility of, so to speak, hereditary (extraopus) transmission in the construction of the primordial idea (or Grundgestalt) of a musical piece. Thus, the analysis was focused on the first of the Four Songs op.2, by Alban Berg, of which the Grundgestalt is presented as a complex formed by several transformations of key-elements extracted from three pieces: Tristan and Isolde, by Richard Wagner, the First Chamber Symphony op.9, by Arnold Schoenberg, and the Piano Sonata op.1, by Berg.

Keywords: Grundgestalt and developing variation; musical symbology; extraopus transmission.

\section{1- Introdução}

0 presente artigo integra uma linha de pesquisa que basicamente visa desenvolver estratégias para a análise de procedimentos construtivos associados aos conceitos de Grundgestalt e variação progressiva, ambos elaborados originalmente por Arnold Schoenberg. Vem dar continuidade a dois estudos prévios sobre a matéria (ALMADA, 2011a; ALMADA, 2011b), nos quais foram estabelecidas as bases da metodologia que é presentemente empregada, abrangendo terminologia, simbologia e elementos gráficos para a análise.

A obra musical aqui focalizada é a primeira (na ordem conológica de composição) das Quatro Canções op.2 de Alban Berg. É especialmente notável nesta peça a existência de relações de derivação profundas e abrangentes que brotam de uma ideia primordial (ou Grundgestalt) composta, resultante da combinação de elementos oriundos de três outras obras: (1) o Prelúdio da ópera Tristão e Isolda de Richard Wagner); (2) a Primeira
Sinfonia de Câmara op.9 de Arnold Schoenberg e (3) a Sonata para Piano op.1, do próprio Alban Berg.

\section{2 - Considerações básicas sobre os conceitos de Grundgestalt e variação progressiva}

Embora tenha sido formulado teoricamente por Schoenberg apenas a partir de 1919 (EMBRY, 2007, p.25), o conceito de Grundgestalt certamente já existia em seu pensamento em épocas bem mais remotas, como demonstra a própria produção musical de sua fase tonal (ver, por exemplo, o Quarteto de Cordas op.7 e a Primeira Sinfonia de Câmara op.9, respectivamente de 1905 e 1906). ${ }^{1}$ Tendo como fundamento filosófico a corrente do Organicismo, surgida no séc. XIX (cujas raízes associam-se ao pensamento de Goethe e Darwin), ${ }^{2}$ a concepção da existência de uma ideia primordial orientadora em uma peça musical, a partir da qual - ao menos de maneira idealizada - todo o material 
construtivo poderia ser extraído (incluindo os elementos contrastantes) teria surgido para Schoenberg, segundo seus próprios depoimentos, após análises minuciosas de obras dos grandes mestres da música germânica: Bach, Mozart, Beethoven e, notadamente, Brahms. ${ }^{3}$ A geração de todo o conjunto de material "genético" de uma peça deve ser realizada, segundo Schoenberg, através de inúmeras transformações (em "direções" e "velocidades" imponderáveis), em um verdadeiro processo de crescimento orgânico denominado variação progressiva (originalmente developing variation). Em suma, a variação progressiva consiste em variações sobre variações, o que gera linhagens consideravelmente extensas, incluindo formas hibridas (que, por sua vez, frequentemente tornam-se base para novas variações). ${ }^{4}$

A partir das elaborações de Schoenberg sobre ambos os conceitos (que se manifestaram mais consistentemente em sua música do que propriamente em seus textos), diversos autores vêm estudando a matéria sob perspectivas tanto teórico-conceituais quanto analíticas, o que se tem intensificado a partir do final da década de $1980 .{ }^{5} 0$ presente estudo, tomando como referência alguns desses trabalhos, tem como meta essencial dar continuidade à elaboração de uma metodologia detalhada para análise a partir de abordagens que privilegiem os aspectos da variação progressiva e de suas relações com a Grundgestalt de uma determinada uma peça musical.

\section{3- As Canções op.2}

Escritas entre 1908 e 1910, as canções que formam o op.2 podem ser consideradas as primeiras obras de Berg como compositor plenamente formado, após a conclusão de seus estudos com Schoenberg, realizados entre 1904 e 1908. ${ }^{6}$ Seus textos são provenientes de dois poetas alemães atuantes em épocas distintas: Friedrich Hebbel (1813-1863), que escreveu o poema Dem Schmerz sein Recht!, usado na primeira canção, e Alfred Mombert (1872-1942), cujo ciclo Der Glühende serviu de base para as três canções finais. No entanto, a sequência definitiva de publicação do op.2 não corresponde à ordem de composição das canções, como revelam pesquisas sobre os esboços de Berg, realizadas por Stephen Kett (apud AYREY, 1982, p.38). De acordo com tal ordem, as duas primeiras canções são sobre textos de Mombert: Schlafend trägt man mich in mein Heimatland e Nun ich der Riesend stärksten überwand (correspondem aos poemas iniciais de Der Glühende), sendo seguidas por Dem Schmerz sein Recht! (texto de Hebbel) e Warm die Luft (o terceiro poema do ciclo de Mombert). Como se trata de um agrupamentos de peças correlatas, é lógico considerar que, para efeito de uma análise derivativa a partir de uma ideia primordial (Grundgestalt), a ordem de composição é um fator de decisiva importância a ser considerado. A primeira canção a ser composta por Berg, portanto, deve constituir a etapa inicial da análise, a ser efetuada no presente estudo.

Diversos autores examinaram o ciclo do op.2 de Berg (e alguns, especificamente, a canção Schlafend trägt man mich in mein Heimatland - identificada, a partir deste ponto, como o op.2/II) sob diferentes perspectivas e graus de profundidade, trazendo importantes contribuições para este estudo: ADORNO (1997) destaca o caráter atemático do grupo de canções, em sintonia com Ewartung de Schoenberg, bem como suas ligações com a obra berguiana antecedente, a Sonata op.1. No entanto, pelo menos em termos, o atematismo sugerido por Adorno pode ser questionado: embora existam, de fato, poucos vínculos rítmico-motívicos consistentes nas canções, percebese, a partir de sua análise no que se refere à dimensão das alturas, associações ideológicas - e derivativas - tão surpreendentes quanto relevantes. Em outras palavras, conexões que não se apresentam nitidamente na superfície musical por estarem desprovidas de seu elemento identificador mais forte, o ritmo. JAMEUX (1980) evidencia as relações entre música e texto presentes nas canções, principalmente aquelas associadas aos conceitos básicos que interligam os poemas de Mombert e Hebbel - sono e morte -, contextualizando-as ainda às situações vivenciadas por Berg naquela época. Este é um ponto de contato com o trabalho de GAULDIN (1999), que examina as diversas referências (musicais e extramusicais) que permeiam o ciclo, resultando em um emaranhado de citações e símbolos que se entranham na estrutura da obra, o que vem a ser uma das principais bases para o presente estudo, como será apresentado. STRAUS (2005) analisa os compassos iniciais do op.2/II de acordo com os princípios da Teoria dos Conjuntos de Classes de Alturas, destacando informações construtivas de grande relevância como, por exemplo, a estrutura cordal de "sexta francesa". Por outro lado - o que vem de encontro aos resultados deste estudo -, esse autor questiona a existência de relações tonais no op.2/II, a despeito da presença da armadura de clave (de Mi bemol-menor) na partitura. É um questionamento também presente no trabalho de AYREY (1982), que traz ainda uma interessante discussão sobre a viabilidade do emprego de ferramentas analíticas neo-schenkerianas em peças de natureza similar. Ambos os tópicos são relevantes para discussão nas conclusões deste artigo. PERLE (1977) comenta a forte predileção de Berg por esquemas de simetria, calcados especificamente no emprego de ciclos simultâneos. Em especial, destaca no início do op. 2/II a superposição de uma sequência em segundas menores descendentes de acordes de "sexta francesa" a um ciclo ascendente de quartas justas. Apresentando outros exemplos desse procedimento composicional (entre eles, a próxima obra de Berg, o Quarteto de Cordas op.3), Perle dá a entender ser ele fruto apenas de uma preferência construtiva do compositor, embora, como será aqui comentado, existam fortes evidências de que sua origem pode estar associada a uma técnica específica desenvolvida por Schoenberg em seu op.9. As relações simétricas também estão no cerne de um artigo de JARMAN (1987) sobre a música do compositor. Sua Célula Básica I [Basic Cel I], embora com nomenclatura e proveniência distintos em relação àqueles considerados no presente estudo, mostra-se como elemento estrutural de crucial importância para o entendimento do processo construtivo da canção analisada. 


\section{4- A Grundgestalt do op.2}

Neste estudo, propõe-se para a Grundgestalt do ciclo op.2 uma concepção inteiramente inusitada e, de certo modo, até mesmo contrária a duas características bem elementares: ${ }^{7}$ (1) a ideia primordial normalmente se apresenta - em sua integridade e de modo claramente reconhecivel - nos compassos iniciais da obra e (2) ela em geral é deduzida a partir de condições estabelecidas pela própria composição. Na forma aqui proposta, a Grundgstalt do ciclo mostra-se como um conjunto de abstrações - como, aliás, acontece na Sinfonia op.9 de Schoenberg e na Sonata op. 1 do próprio Berg (ALMADA, 2011a; 2011b). Ela, portanto, apresenta-se não como uma unidade simples, mas como uma construção composta, derivada da combinação de elementos-chave - e até mesmo arquetípicos - advindos de outras obras: além das duas acima mencionadas, acrescente-se o Prelúdio de Tristão e Isolda de Wagner. Isso conduz quase que naturalmente à hipótese de uma geração de Grundgestalt a partir de transmissão hereditária ou genética, por assim dizer. Como deixa claro GAULDIN (1999) - que evidencia a existência das referências a Tristão e Isolda no op.2 de Berg aqui consideradas -, a motivação para o emprego de tais elementos extraopus nas canções teria uma forte carga simbólica, associada principalmente à paixão do compositor por aquela que posteriormente se tornaria sua esposa, Helene Nahowsky. ${ }^{8}$

0 Ex.1 apresenta a Grundgestalt composta do op.2, a partir da tripla fonte referencial, dividindo-se em dois ramos principais: $\mathrm{T}$ (de Tristão) e $\mathrm{K}$ (de Kammersymphonie - a designação original em alemão para a Sinfonia de

(a)
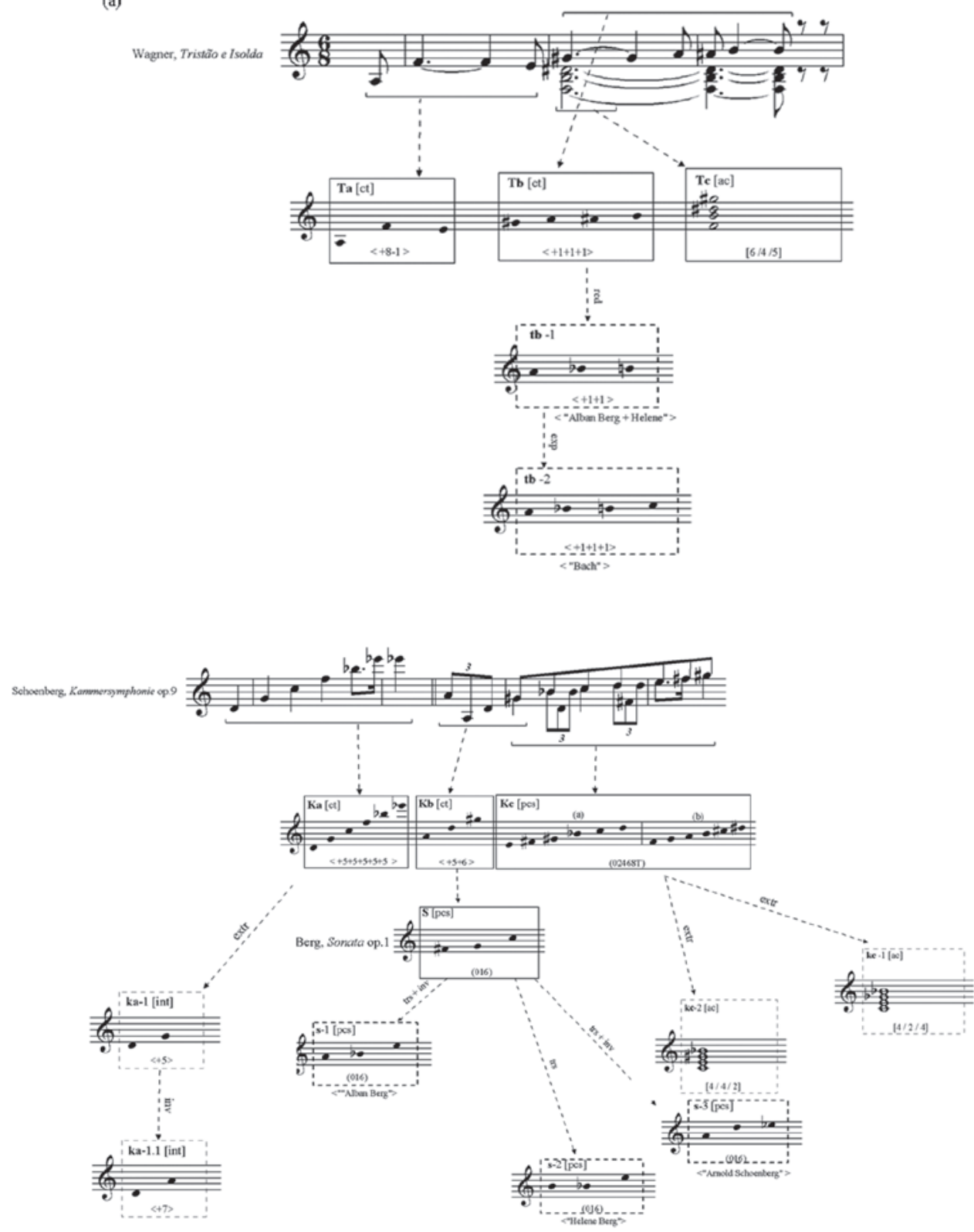

Ex.1 - Complexo-Grundgestalt das Quatro Canções op.2 de Berg, a partir de derivações do Prelúdio de Tristão e Isolda de Wagner (a) e da Kammersymphonie op.9 de Schoenberg (b) 
Câmara). Observe-se que o ramo S (de Sonata) é subordinado por derivação a K, o que evidencia a estreita relação de influência que conecta ambas as obras. ${ }^{9}$ 0 complexo resultante é inteiramente constituído de abstrações, denominadas Grundgestalten auxiliares (ou GG, os retângulos cheios) e, hierarquicamente subordinadas a estas, Grundgestalten intermediárias (gg, os retângulos tracejados).

Essa vasta e abrangente conjunção de elementos corresponde, portanto, às ideias construtivas básicas que geram a totalidade (ou quase) do material melódicoharmônico que compõe as Canções op.2.

A simbologia aqui adotada requer uma breve explanação. Cada um dos retângulos (seja GG ou gg) apresenta algumas informações que os definem:

- Proveniência (em negrito, no vértice superior esquerdo), ou seja, a relação parental de derivação (p.ex., tb-1, a partir de Tb). 0 tipo de inicial está associado à hierarquia derivativa: maiúscula para Grundgestalt auxiliar (GG) e minúscula paraGrundgestalt intermediária (gg);

- Característica principal da forma (entre colchetes, ao lado da proveniência), podendo ser uma das seguintes categorias abstratas: acorde [ac], intervalo [int], contorno melódico [ct], conjunto de classes de alturas [pcs - como abreviatura de pitch-class set];

- Especificação da característica (centralizada no lado inferior do retângulo), considerando as seguintes convenções:

- <...> - sequência de intervalos sucessivos (para contorno melódico). Ex.: $<+1+2-7>,{ }^{10}$ indicando a série intervalar segunda menor ascendentesegunda maior ascendente-quinta justa descendente;

- [....... - sequência de intervalos simultâneos (para acordes), no sentido grave-agudo. Ex: [3/4] indica a disposição de uma tríade menor;

- (...) - forma primordial de um conjunto de classes de alturas não serializadas (usado para pitch-class sets). Ex: (013).

- Simbologia extramusical associada à forma (sob o retângulo), entre chevron e aspas (p. ex: <"Alban Berg">);

- As derivações são indicadas por setas tracejadas, às quais eventualmente são associadas abreviaturas dos tipos de operações empregadas (extração, transposição, expansão, inversão etc.). ${ }^{11}$

As informações acima apresentadas permitem identificar precisamente todas as derivações obtidas a partir dos elementos básicos presentes em cada um dos dois ramos principais. No primeiro deles, derivado de Tristão e Isolda (Ex.1a), três ideias motívicas (presentes justamente nos três compassos iniciais e que, por si só, sintetizam essa obra wagneriana) tornam-se os modelos para as subsequentes abstrações: o gesto melódico inicial Lá-
Fá-Mi (originalmente desempenhado por um oboé desacompanhado), a linha cromática ascendente que se segue, Sol\#-Lá-Lá\#-Si, e a tétrade meio-diminuta que a sustenta, o assim chamado "Acorde Tristão". Disso resultam três GG's, respectivamente, $\mathrm{Ta}$ [ct],Tb [ct] e Tc [ac]. De Tb são obtidas duas gg's variantes: tb-1 [ct], por redução (de quatro para três notas) e transposição, de modo a fazer surgir a sequência Lá-Sib-Si (na notação musical alemã, ABH, simbolizando "Alban Berg + Helene") e tb-1.1 [ct], que reexpande a forma anterior para quatro notas, porém sem transpô-la: Lá-Sib-Si-Dó (ABHC, um anagrama de "Bach", tema bastante recorrente entre os membros da Segunda Escola de Viena). ${ }^{12}$

0 segundo ramo (Ex.1b) apresenta também três elementos motívicos básicos que resumem as principais relações estruturais existentes na Kammersymphonie: a sequência de cinco quartas justas ascendentes, tratadas na obra schoenberguiana tanto melódica quanto harmonicamente (abstraída em $\mathrm{Ka}[\mathrm{ct}]$ ), a anacruse do tema principal, que descreve o contorno ascendente quarta justa-quarta aumentada (Kb $[\mathrm{ct}]$ ) e a primeira frase desse mesmo tema, construída a partir da escala de tons inteiros (Kc [pcs], que se desdobra em suas duas únicas possíveis coleções, convencionadas como $a$ e $b$ ). Essas três GG's dão origem a um número muito maior de formas do que no caso anterior:

- a partir da redução do âmbito de Ka [ct] resultam as díades: ka-1 [int] (o intervalo isolado de quarta justa) e ka-1.1 [int] (sua inversão, a quinta justa);

- a partir da redução do âmbito de Kc[pcs] resultam os tetracordes: kc-1 [ac] (a tétrade "dominante" com quinta diminuta, também conhecida como "acorde de sexta francesa") e kc-2 [ac] (tétrade "dominante" com quinta aumentada);

- a partir da transformação de Kb [ct], de segmento serializado (quarta justa-quarta aumentada) a tricorde de alturas não ordenadas, passivel de sofrer todo tipo possível de permutação. É este, de todos, o elemento construtivo mais importante na dimensão das alturas (especialmente no op.2/II). Suas derivações são intermediadas pelo sub-ramo $S$ [pcs], que retrata a enorme importância desse conjunto na estrutura da Sonata op. 1 berguiana. ${ }^{13}$ Três gg's são obtidas, a partir de transposições e/ ou inversões desse tricorde, todas elas resultando em associações pessoais simbólicas: s-1 (ABE, para "Alban Berg"), s-2 (HBE, para "Helene Berg") e s-3 (ADS, para "Arnold Schoenberg"). ${ }^{14}$

Em resumo, as diferentes formas que constituem a Grundgestalt composta da obra (ou, numa nomenclatura alternativa, seu complexo-Grundgestalt - a partir deste ponto, c-G) são empregadas, em maior ou menor medida, na construção das quatro peças do op.2, abrangendo assim a quase totalidade de seus conteúdos melódicoharmônicos (incluindo ainda formulações delas derivadas, que serão apresentadas oportunamente). Como etapa 
inicial da análise completa do ciclo, as próximas seções deste estudo examinam específicamente as relações derivativas presentes na primeira canção, Schlafend trägt man mich in mein Heimatland (op.2/II). ${ }^{15}$

\section{5 - Análise derivativa do op.2/II (c.1-4) ${ }^{16}$}

0 Ex.2 apresenta os quatro compassos iniciais da canção (Ex.1a), bem como uma redução do mesmo trecho (utilizando uma adaptação livre da metodologia analítica schenkeriana), ${ }_{1}^{17}$ na qual são indicadas três relações derivativas associadas ao c-G (Ex.1b): (1ª) alternância entre as coleções $a$ e $b$ da escala de tons inteiros (a partir de Kc [pcs]); (2a) sucessão de acordes de "sexta francesa", delimitados pelos retângulos sombreados (a partir de kc-1 [ac]) e (3a) linha de baixo em sequência de quartas justas ascendentes (a partir de Ka [ct]).

Ao menos neste trecho inicial fica evidente a existência de uma forte influência do ramo K (ou seja, oriundo da Sinfonia) sobre a construção do op.2 de Berg. Na verdade, é possível afirmar que a reverberação dessa obra de Schoenberg sobre a mente criativa de seu antigo aluno apresentar-se-ia ainda bastante intensa, não tendo se dissipado após a composição da Sonata op.1. Em relação ao trecho específico aqui analisado, pode-se encontrar o modelo de sua concepção no ponto climático da seção de desenvolvimento (parte III) da Sinfonia (c.358-9). As semelhanças são notáveis (ver Ex.3 em comparação com o Ex.2).

Nas duas pautas superiores desenrola-se um diálogo imitativo entre linhas que se referem explicitamente ao tema principal da Sinfonia, representado pelo seu fragmento anacrústico (ver Ex.1b), aqui adaptado à escala de tons inteiros. Sobreposto a tal textura, na pauta inferior, o tema quartal é apresentado em sua integridade. ${ }^{18} \mathrm{~A}$ construção é planejada de modo que a cada tempo sejam alternadas as duas coleções da escala de tons inteiros (os retângulos acinzentados facilitam a observação vertical dessa alternância). Nos termos do presente estudo, podemos sintetizar o próprio processo construtivo (ou seja, a superposição dos dois materiais básicos, a escala de tons inteiros e a sequência de quartas), atribuindo-Ihe a criação de uma nova forma $\mathrm{gg}$, por hibridismo, designada pela fórmula $\mathrm{ka}+\mathrm{kc}$, que assim junta-se às demais derivações.

Sob uma outra perspectiva - puramente melódica -, os quatro compassos iniciais do op.2/ll fornecem novas informações de grande importância. Duas ideias temáticas dialogam em contraponto: a linha do canto e a voz mais aguda dos acordes da mão direita do piano (Ex.4).

(a)
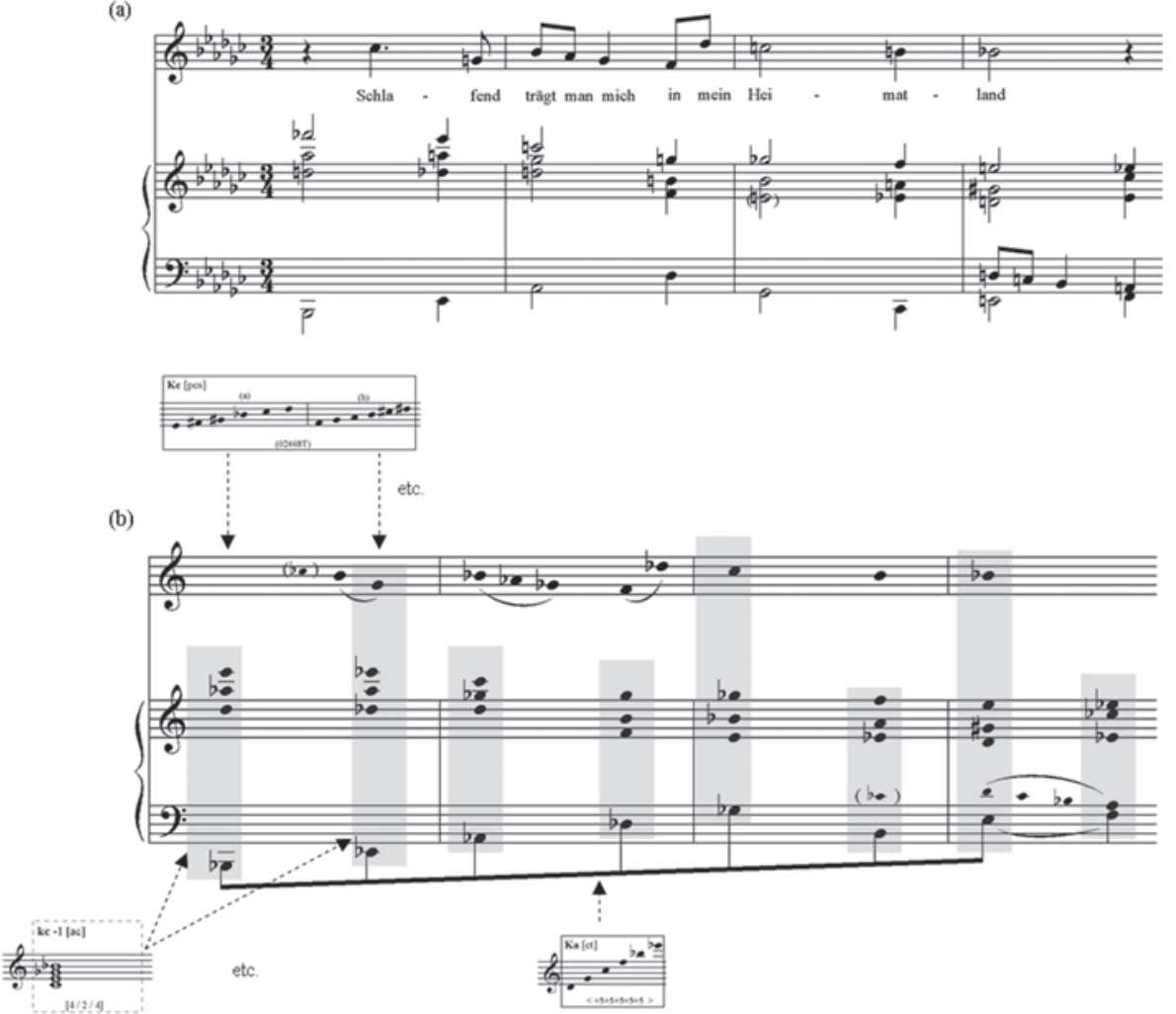

Ex.2 - Berg - op.2/II (c.1-4): superfície (a); redução analítica (b) 


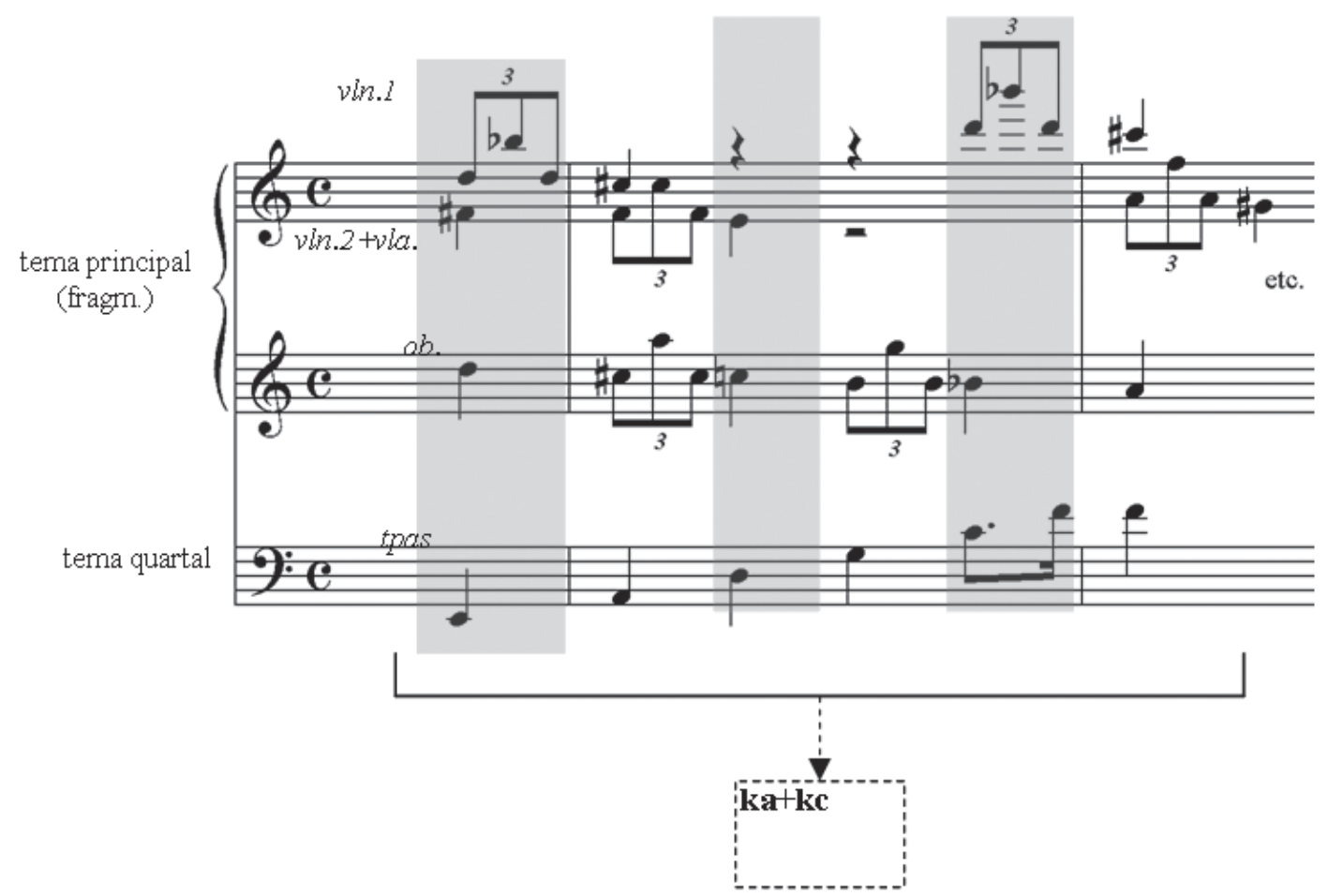

Ex.3 - Schoenberg - Sinfonia de Câmara op.9 (c.358-9) (redução)

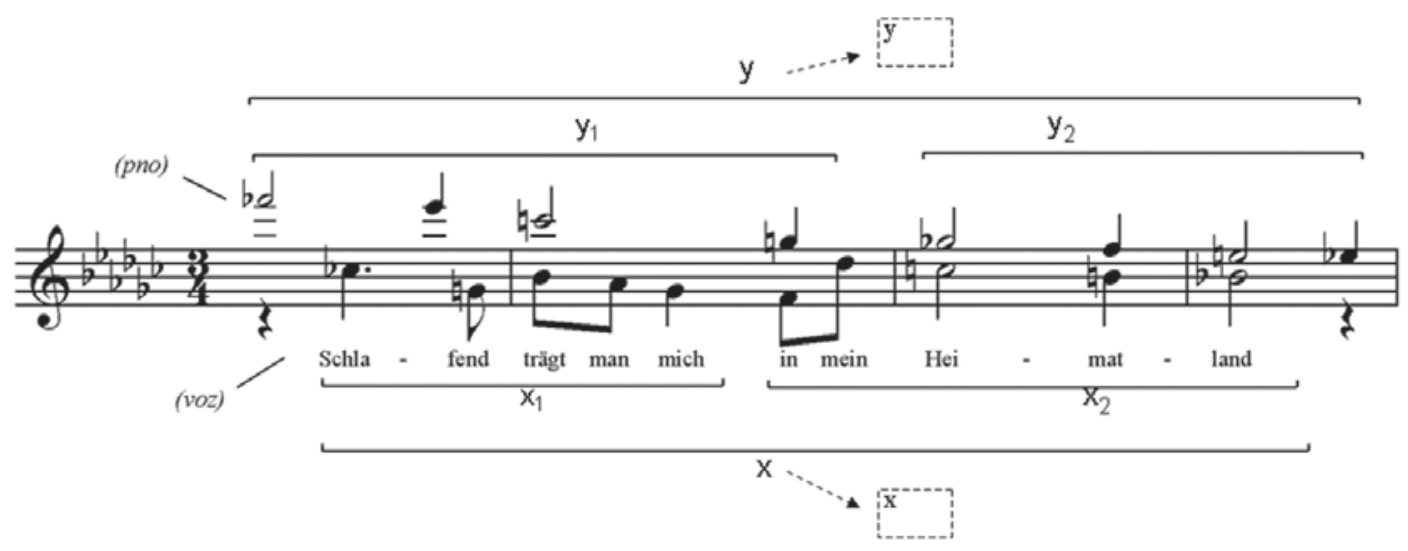

Ex.4 - Berg - op.2/II (c.1-4): contraponto entre ideias temáticas $x$ e $y$

As duas ideias temáticas têm suas respectivas identidades associadas mais ao aspecto dos contornos intervalares do que às suas configurações rítmicas correspondentes. São nomeadas como $x$ e $y$, tendo em vista a ausência de referências derivativas evidentes em relação à Grundgestalt composta da peça (a necessidade das subdivisões $x_{1} / x_{2} e$ $\mathrm{y}_{1} / \mathrm{y}_{2}$ será explicitada mais adiante). Constituem, portanto, formas fenotípicas, em oposição àquelas presentes no c-GG, designadas como genotípicas. ${ }^{19}$

Ainda que mostrem-se como elementos autônomos da superfície e, por assim dizer, idiossincráticos, surgidos de condições únicas dessa canção específica (ou seja, não estando necessariamente associados em parentesco com as demais peças do ciclo), relações "subcutâneas" com elementos genotípicos podem ser detectadas nas formas $x$ e y, como mostram as análises dos Exs.5, 6 e 7.

É possivel observar no Ex.5 que a estrutura de x está associada à GG S [pcs], em três níveis de organização (cada qual representado por uma trave horizontal ligando hastes de algumas das alturas, na parte superior da pauta), sendo hierarquicamente mais importante aquele que é apoiado sobre as notas Si (início de $x_{1}$ ), Fá (início de $x_{2}$ ) e Sib (final de $x_{2}$ ). A forma-motivo Fá-Réb-Dó (ligada pela trave na parte inferior da pauta) que abre o segmento inicial de $x_{2}$, por sua vez, revela uma clara relação com a GG Ta [ct]. ${ }^{20}$ Como será visto, tal elemento derivado do ramo "wagneriano" tem também atuação decisiva na estrutura melódica desta canção. 


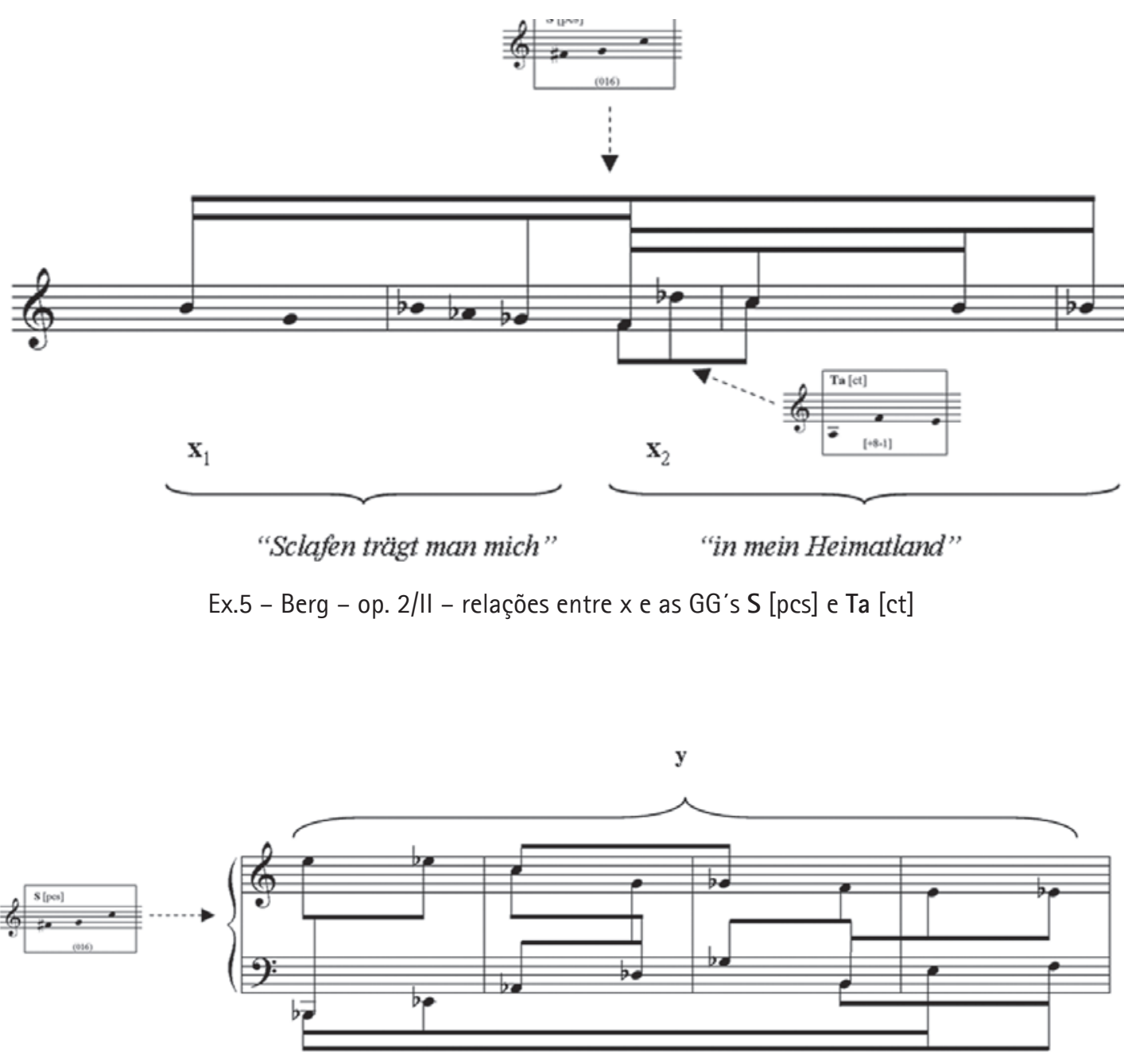

Ex.6 - Berg - op. 2/II - relações entre y (associado à linha do baixo) e a GG S [pcs]

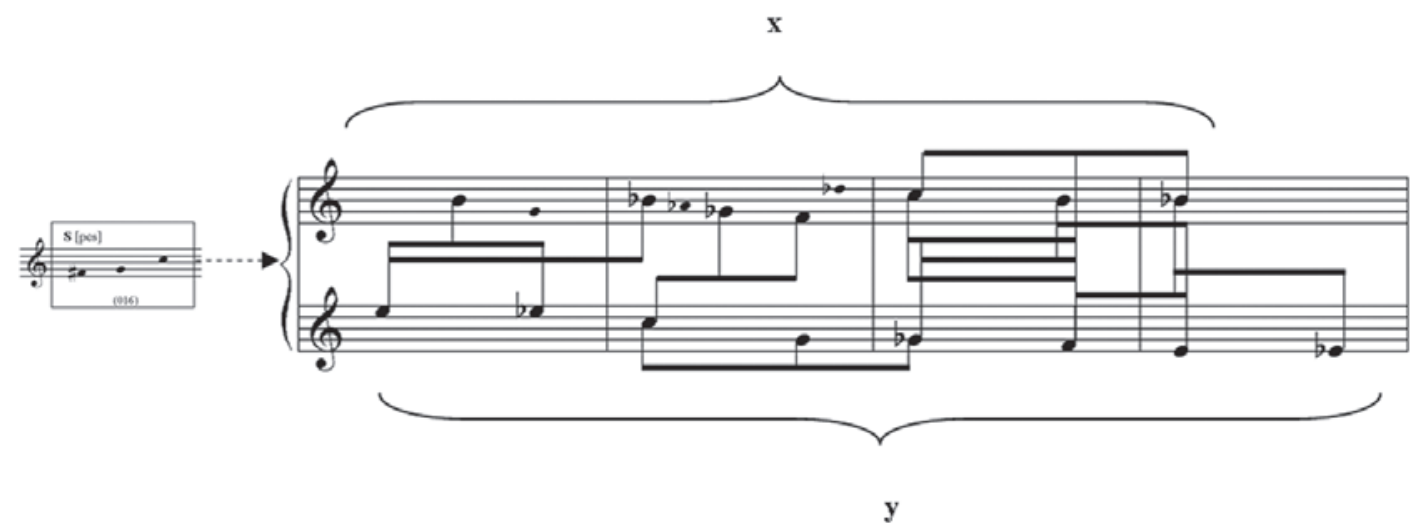

Ex.7 - Berg - op. 2/II - relações entre x e y (associados) e a GG S [pcs]

Em y (Ex.6) as relações com $S$ [pcs] são também múltiplas, especialmente se for levada em conta a associação simultânea dessa ideia temática (pauta superior) com a linha do baixo do piano (em sequência de quartas - comparar com o Ex.2).
A marcante presença de $\mathrm{S}$ [pcs] nas estruturas de $\mathrm{x}$ e y pode ser ainda ressaltada por intermédio de uma análise abrangendo ambas as formas simultaneamente: nada menos do que onze referências ao tricorde podem ser detectadas nesse contraponto (Ex.7) 


\section{6 - Análise derivativa do op.2/II (perspectiva global)}

A partir das informações coletadas, é possível iniciar a análise derivativa de toda a canção sob uma perspectiva global, de modo não apenas a examinar as relações de seu conteúdo com o c-GG (que abrange todo o ciclo), como também evidenciar eventuais papéis estruturalizantes dos procedimentos de variação progressiva. É interessante perceber que o viés do binômio derivação/variação desvenda alguns aspectos que seriam inacessiveis sob outras abordagens.

0 Ex.8 apresenta o bloco inicial da peça (c.1-7), subdividido em duas seções: a primeira delas (c.1-4) corresponde aos dois versos iniciais do texto, consistindo numa espécie de enunciado principal, marcado pela presença das três ideias principais, $x, y$ e a linha quartal do baixo (é também pertinente acrescentar ao grupo a forma gg híbrida ka+kc). Sob a perspectiva da análise neo-schenkeriana percebe-se como o evento harmônico inicial - o dominante alterado ("sexta francesa") da tonalidade central, Mib-menor - é prolongado, a despeito das alternâncias das coleções da escala de tons inteiros e da curva em quartas ascendentes. 0 acorde inicial, desta vez invertido, retorna quando o baixo atinge a nota $\mathrm{Mi}^{21}$

A seção 2 (c.4.3-8.2) consiste numa espécie de interlúdio instrumental, no qual acontece um diálogo imitativo envolvendo derivações de Ta e de S. ${ }^{22}$ A partir do c.7 0 contraponto se intensifica, com a diminuição das distâncias entre as imitações, associada a uma gradual ascensão para o registro agudo do piano, o que constitui nitidamente um processo de liquidação, propício para finalização formal. ${ }^{23}$

A conclusão da segunda seção é marcada por um evento derivativo importante, que prepara propriamente 0 retorno do canto (ver Ex.9): após uma última transposição

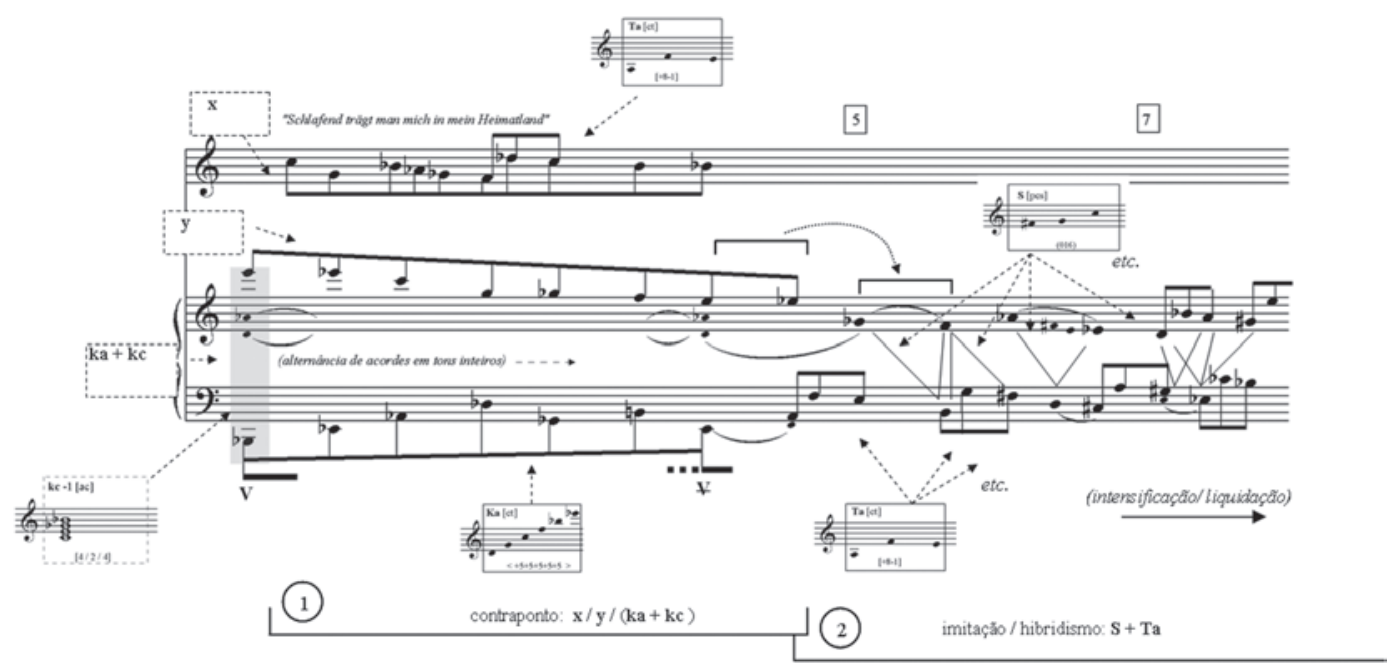

Ex.8 - Berg - op. 2/II - análise derivativa: seções 1 e 2 (c. 1-7)

(a)

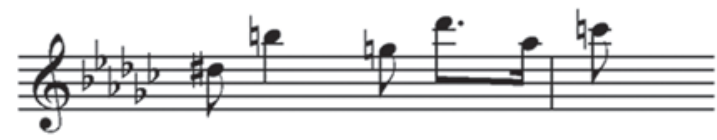

(b)

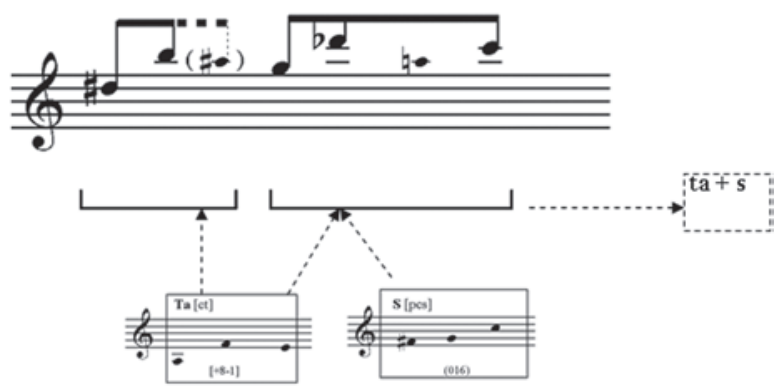

Ex.9 - Berg - op. 2/II - final da seção 2 (c.8-9.1), linha mais aguda do piano (a) redução (b) 
de Ta que é, no entanto, interrompida (por elisão da nota Lá\#, indicada entre parênteses no Ex.9b), surge uma versão transformada, com a substituição do intervalo ascendente inicial da fórmula (sexta menor) por uma quinta diminuta. Tal alteração implica o surgimento de uma nova gg hibrida: ta+s.

A seção 3 (c.8.3-13.1) inicia-se no tempo que antecede a entrada do terceiro verso do canto, ponto onde surge finalmente o I grau da tonalidade central, ${ }^{24} 0$ que enfatiza sua função articuladora (Ex.10). 0 trecho é marcado por uma intensa reformulação das ideias temáticas $x$ e y: estas são permutadas, com a inversão de suas posições originais (comparar com o Ex.8), sequenciadas $^{25}$ e fragmentadas (com a utilização das primeiras metades $\mathrm{x}_{1}$ e $\mathrm{y}_{1}$ ). Harmonicamente, o caráter do trecho é também contrastante, pois, pela primeira vez na peça, a alternância das coleções $a$ e $b$ (da escala de tons inteiros) é temporariamente abandonada, dando lugar a uma superposição deslocada desses elementos. Uma interessante reformulação da GG Ka (ainda que um tanto disfarçada, pela apresentação simultânea de algumas das notas) pode ser constatada na mão esquerda do piano (c.10-13): Dó-Fá/Sib-Mib/Láb-Réb. A seção 4 inicia-se no c.13, articulada pelo retorno do ambiente harmônico inicial, com a alternância dos acordes de "sexta francesa" em movimento cromático descendente. É uma passagem curta, correspondendo ao penúltimo verso do poema, que prepara a seção final, uma espécie de recapitulação concentrada (ver Ex.11).

Berg engenhosamente aproveitou-se do fato de o verso conclusivo do poema ser uma repetição literal do segundo ("In mein Heimatland" / "[de volta] à minha

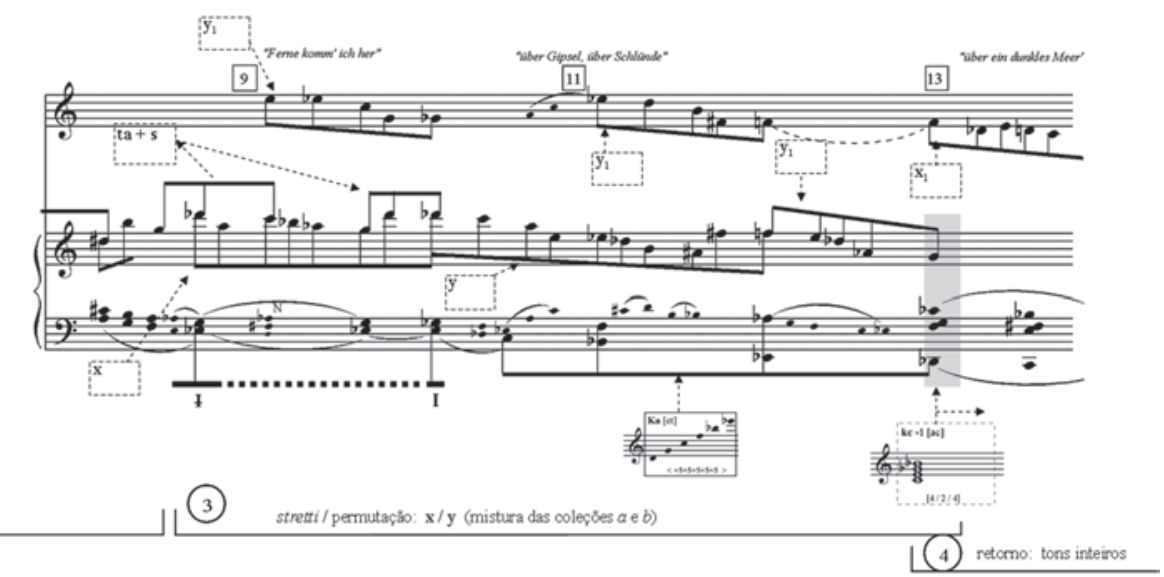

Ex.10 - Berg - op. 2/II - análise derivativa: seções 2-4 (c.8-13)

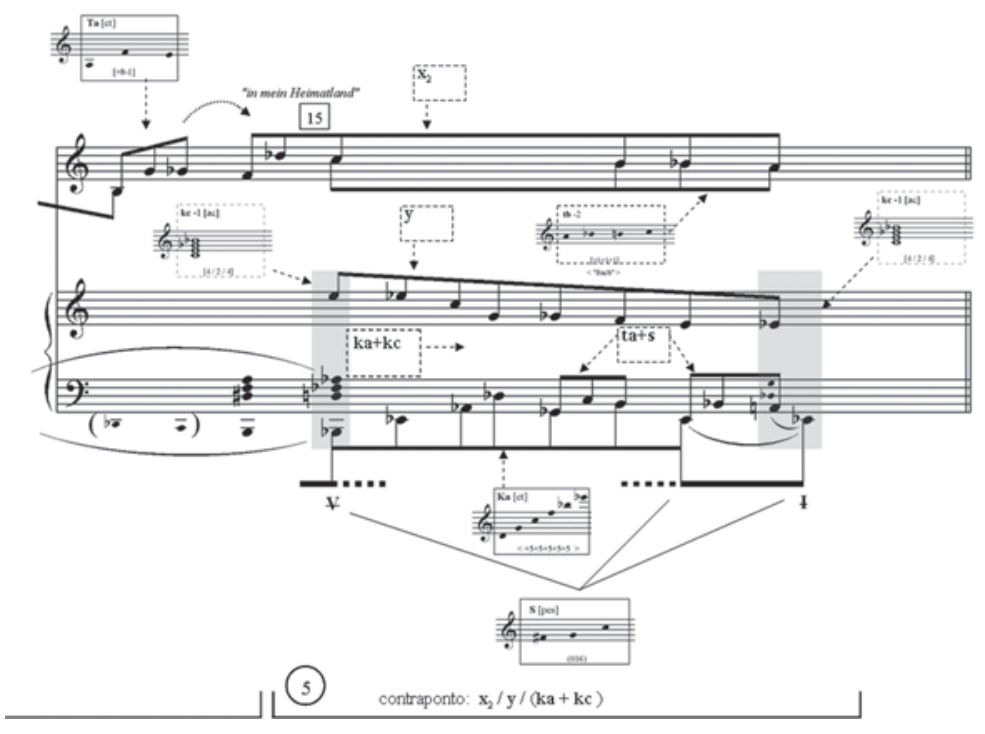

Ex.11 - Berg - op. 2/II - análise derivativa: seções 4-5 (c.14-18) 
pátria"), fazendo retornar o bloco de ideias iniciais, porém de um modo mais compactado. A construção é também notável pelo tratamento metafórico que revela: um retorno definitivo, após as digressões/viagens (seções 2 a 4). Diversos pontos merecem comentários detalhados (comparar os Exs.11 e 8):

(a) a linha do canto é aqui resumida apenas à segunda metade $\left(\mathrm{x}_{2}\right)$ da ideia temática original;

(b) a sílaba final (que no primeiro verso corresponde a Sib) é estendida a mais um degrau na escala cromática descendente, chegando à nota Lá (como que expressando um retorno definitivo e concreto, antes apenas imaginado). Isso faz com que o conjunto de alturas que formam o segundo "Heimatland" corresponda à gg tb-2 (o anagrama de "Bach"), o que não parece ser de modo algum fortuito;

(c) no aspecto harmônico/tonal observa-se o retorno da preparação dominante, bem como de sua prolongação - no trecho dos c.1-4 -, finalmente dirigindo-se à resolução (reforçando, portanto, o caráter de retorno $)^{26}$ que, no entanto, acontece mais uma vez sobre o I grau em modo maior:27

(d) os baixos desses três acordes formam o conjunto (016), ou seja, estão relacionados a S [pcs];

(e) tanto a linha do baixo quanto a linha superior dos acordes (y) apresentam-se em sua integridade, porém em diminuição rítmica livre em relação ao trecho inicial. É digna de menção a presença da variante híbrida ta+s (surgida na seção 3) na mão esquerda do piano.

Todos esses fatos parecem querer expressar uma volta ao lar enriquecida por novas experiências, o que revela, por si só, uma relação profunda e sofisticada entre texto e música e, consequentemente, o perfeito domínio do compositor sobre os elementos estruturantes.
Finalizando esta análise, o Ex.12 apresenta uma visão global (uma quase-Ursatz, por assim dizer) ${ }^{28}$ abrangendo o grupo das três canções inciais. ${ }^{29}$ A relações observadas nesse nivel fundamental são ainda mais surpreendentes, revelando um planejamento apoiado marcadamente na recursividade da GG S [pcs], o que confere a este elemento o papel principal na hierarquia da construção tonal do ciclo. Como se vê no Ex.12, não apenas os vários pontos de apoio - internos e entre as canções - como as próprias tonalidades associam-se na relação (016). ${ }^{30}$

0 Ex.13 apresenta uma redução do Ex.12, na qual são destacadas apenas as relações entre os pontos estruturais e a GG S [pcs], sem hierarquizá-las, o que traz ainda à tona novas associações contíguas.

\section{7 - Conclusões}

Este estudo vem confirmar o pressuposto de que os conceitos de Grundgestalt e variação progressiva fincaram profundas raízes na concepção criativa de Berg, a partir de seus estudos com Schoenberg. ${ }^{31}$ Pela presente proposta, é possivel concluir que tais elementos atuam como principais orientadores na estruturação das Quatro Canções op.2 e, especificamente, na primeira delas a ser composta, Schlafen trägt man mich in mein Heimatland. É ainda bastante relevante acrescentar que a ideia primordial do ciclo - sua Grundgestalt - apresentase inusitadamente como uma estrutura composta, resultante da aglutinação de materiais-chave derivados de duas obras emblemáticas para o compositor: Tristão e Isolda e a Primeira Sinfonia de Câmara. No primeiro caso, a partir de associações musicais aos projetos amorosos de Berg, e no segundo, de sólidas referências a procedimentos composicionais apreendidos de seu mestre. No que se refere à peça aqui analisada, observase que as Grundgestalten auxiliares associadas ao ramo da Sinfonia schoenberguiana apresentam-se como a

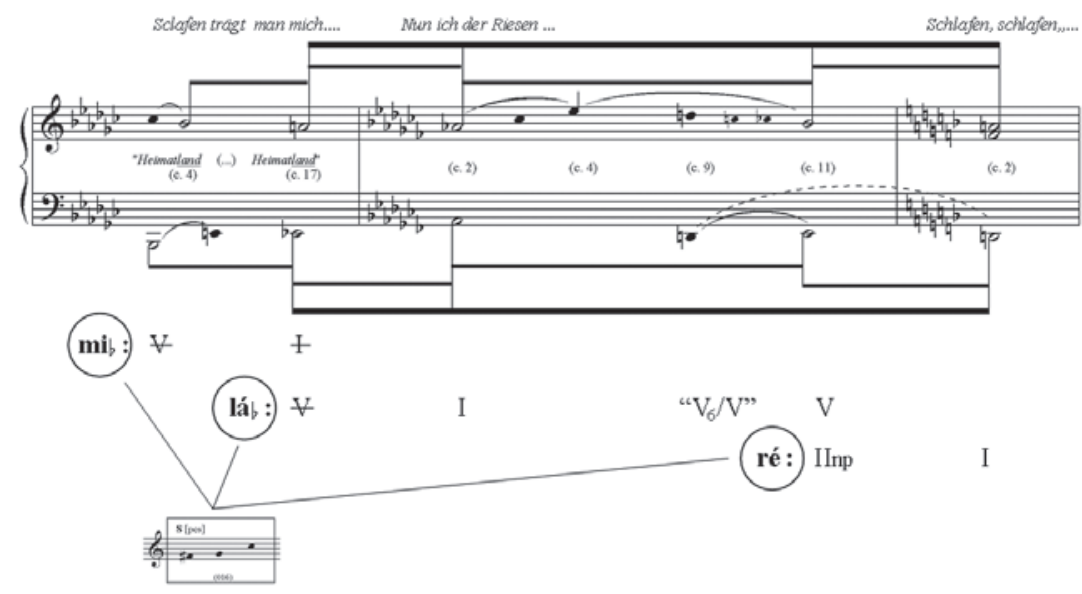

Ex.12 - Berg - op. 2 - relações estruturais-tonais entre as três primeiras canções do ciclo 


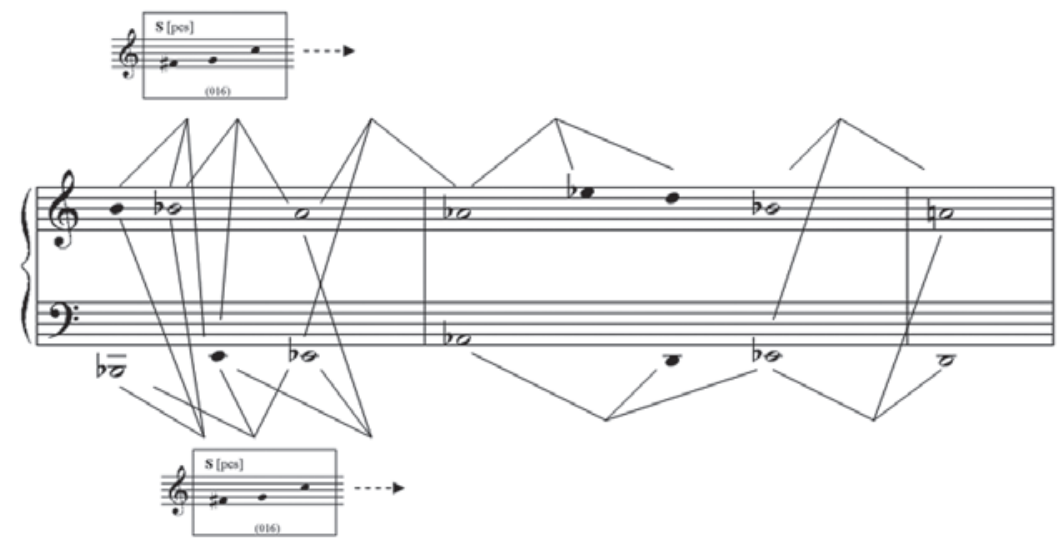

Ex.13 - Berg - op. 2 - redução do Ex.12

principal fonte estruturadora: a sequência quartal ( $\mathrm{Ka}$ [ct]), a escala de tons inteiros (Kc [pcs]) e, especialmente, o set-class (016), obtido da transformação da anacruse do tema principal do op.9 (Kb [ct]) em conjunto de alturas não ordenadas (S [pcs]), uma derivação intermediada pela obra berguiana que precede o op.2, a Sonata para Piano.

A hipótese aqui apresentada permite ainda que sejam melhor entendidas as motivações e as razões das escolhas de Berg para a concepção do ciclo. Os diversos autores mencionados no corpo do texto analisam a obra sob as mais diversas perspectivas, muitas delas complementares a este estudo, mas, a despeito de serem todas, em seus próprios termos, elucidativas, atraentes e detalhadas, em nenhuma delas é considerada a derivação como principal força de organização estrutural. Mesmo GAULDIN (1999), ao propor diversas associações e referências extra e intramusicais como fator crucial para o entendimento das canções berguianas, deixa de lado o papel central construtivo que é desempenhado pela influência advinda de Schoenberg (e, mais especificamente, da Sinfonia op.9), o que constitui, lamentavelmente, uma lacuna em seu importante trabalho.

Em relação à metodologia analítica, os resultados obtidos neste estudo representam um aperfeiçoamento do trabalho que vem sendo desenvolvido na pesquisa sobre 0 assunto. Os elementos gráficos derivados da análise schenkeriana, associados aos recursos previamente estabelecidos revelaram-se uma estratégia eficaz, embora ainda passivel de refinamentos.

É muito interessante constatar que a análise global do op. 2/II a partir da abordagem derivativa (evidenciada pelos Exs.8, 10 e 11) trouxe à tona uma insuspeitável arquitetura de forma-sonata, ainda que com certas liberdades em relação ao convencional e bastante concisa: ${ }^{32}$ seção 1 Exposição simultânea dos dois "grupos temáticos", x e y (c.1-4); seção 2 - Transição (c.4-8); seção 3 - espécie de Desenvolvimento, com fragmentação e sequenciação de $x$ e y, tratados imitativamente e em ambiente harmônico contrastante (c.9-13); seção 4 - Retransição, com retorno ao contexto harmônico original; seção 5 - Reexposição compactada, finalizando em cadência "autêntica".

Embora tenham sido aqui pouco comentadas neste estudo, as relações entre texto e música, evidentemente, também representam uma questão importante para o entendimento da obra, e serão reservadas para um exame mais aprofundado nas etapas subsequentes da pesquisa, após (ou simultaneamente a) a análise derivativa das canções restantes. 


\section{Referências}

ALMADA, Carlos de L. "Nas fronteiras da tonalidade": Tradição e inovação na forma da Primeira Sinfonia de Câmara, op.9, de Arnold Schoenberg. 2007. Dissertação (Mestrado em Música) - Centro de Letras e Artes, Universidade Federal do Estado do Rio de Janeiro.

Pontos de contato entre a Sonata para Piano,op.1, de Alban Berg e a Primeira Sinfonia de Câmara,op.9, de Arnold Schoenberg. In: V SIMPÓSIO DE PESQUISA EM MÚSICA - SIMPEMUS 5, 2008. Curitiba. Anais ...Curitiba: UFPR, 2008.

A variação progressiva aplicada na geração de ideias temáticas. In: // Simpósio Internacional de Musicologia. Rio de Janeiro: UFRJ, 2011 a.

. Derivação temática a partir da Grundgestalt da Sonata para Piano op.1, de Alban Berg. In: II Encontro Internacional de Teoria e Análise Musical. Anais ...São Paulo: UNESP-USP-UNICAMP, 2011b. 1 CD-ROM (11p.).

ADORNO, Theodor W. Alban Berg (Juliane Brand \& Christopher Hailey, trad.). Cambridge: CambridgeUniversity Press, 1997.

AYREY. Craig. Berg's 'Scheideweg': Analytical issues in Op. 2/ii. Music Analysis, vol. 1, no 2, 1982, p.189-202

BOSS, Jack. Schoenberg's Op. 22 radio talk and developing variation in atonal music. Music Theory Spectrum, vol. 14, $\mathrm{n}^{\circ}$ 2, 1992, p.125-149.

BURTS, Devon. An application of the grundgestalt concept to the First and Second Sonatas for Clarinet and Piano, Op. 120, no. 1 Et no. 2, by Johannes Brahms. 2004. Dissertação (Mestrado em Música) - University of South Florida.

CARPENTER, Patricia. Grundgestalt as tonal function. Music Theory Spectrum, vol. 5, 1983, p.15-38.

DUDEQUE, Norton. Variação progressiva como um processo gradual no primeiro movimento do Quarteto A Dissonância, K. 465, de Mozart. PerMusi, vol.8, UFMG, 2003, p.41-56.

Publishings, 2005.

Music theory and analysis in the writings of Arnold Schoenberg (1874-1951). Aldershot: Ashgate

EMBRY, Jessica. The role of organicism in the original and revised versions of Brahms's Piano Trio In B Major, Op. 8, Mvt. I:A comparison by means of Grundgestalt analysis. 2007. Dissertação (Mestrado em Música) - University of Massachusetts Amherst.

FRISCH, Walter. Brahms and the principle of developing variation.Los Angeles: University of California Press, 1984.

GAULDIN, Robert. Reference and association in the Vier Lieder, Op. 2, of Alban Berg.Music Theory Spectrum, vol. 21, n 1, 1999, p.32-42.

HAIMO, Ethan. Developing variation and Schoenberg's serial music. Musical Analysis, vol. 16, no 3, p.349-365,1997.

HILMAR, Rosemary. Alban Berg's studies with Schoenberg.Journal of the Arnold Schoenberg Institute, Los Angeles, vol. VIII, n' 1, p.7-29, 1984.

JAMEUX, Dominique. Berg. Bourges: Solfèges, 1980.

JARMAN, Douglas. Alban Berg: The origins of a method. Music Analysis, vol. 6, n 3, p.273-288, 1987.

MARTINEZ, Alejandro. La forma-oración en obras de la Segunda Escuela de Viena: un lectura desde la morfología de Goethe. Revista del Instituto Superior de Música, no.12, Santa Fe, p.96-113, 2009.

MEYER, Leonard. Style and music. Chicago: The University of Chicago Press, 1989.

PERLE, George. Berg's Master array of the interval cycles. The Musical Quarterly, nol. 63, n 1, 1977, p.1-30.

SALZER, Felix. Structural hearing: Tonal coherence in music (2 vol.). Nova lorque: Charles Boni, 1952.

SCHOENBERG, Arnold. Style and idea: selected writings of Arnold Schoenberg. (Leonard Stein, ed.). Londres: Faber \& Faber, 1984.

Fundamentals of musical composition.(Gerald Strang, ed.) Londres: Faber \&t Faber, 1990.

STRAUS, Joseph. Introduction to post-tonal theory (3 ed.). Englewood Cliffs: Prentice-Hall, 2005.

STUCKENSCHMIDT, H. H. Schönberg: vida, contexto, obra. (Ana Agud, trad.). Madri: Alianza Editorial S.A., 1991.

TOOP, Richard. Stockhausen, Kalheinz. In: New Grove Dictionary of Music. Oxford: Oxford University Press, 2001. 


\section{Notas}

1 Para uma análise detalhada da Grundgestalt da Sinfonia op.9, ver ALMADA (2011a).

2 Para Organicismo e a influência das descobertas de Darwin sobre a música romântica, ver MEYER (1989, p.189-96). Para o papel de Goethe na elaboração do conceito de Grundgestaltpor Schoenberg, ver BURTS (2004, p.7-9) e MARTINEZ (2009).

3 Para destacar a importância do tratamento derivativo de Brahms, Schoenberg apresentou na Rádio Frankfurt em 1933 uma palestra intitulada "Brahms, o progressivo", que seria tranformada em um ensaio de mesmo título, publicado em 1950 na coletânea Style and Idea (SCHOENBERG, 1984, p.398-441). Para outros trabalhos mais recentes sobre variação progressiva e Grundgestalt na música de Brahms, ver FRISCH (1984), BURTS (2004) e EMBRY (2007).

4 Entre inúmeras definições de variação progressiva já produzidas na literatura analítica, Ethan Haimo afirma que ela consiste em "uma categoria especial da técnica de variação, implicando um processo teleológico. Como um de seus resultados, eventos de maior escala - mesmo aqueles marcadamente contrastantes - podem ser entendidos como originados (ou brotados) das mudanças que foram feitas nas repetições das unidades musicais anteriores. Portanto, a verdadeira variação progressiva pode ser distinguida das repetições variadas meramente locais que não possuem consequências por desenvolvimento" (HAIMO,1997, p.351).

5 Ver, por exemplo, EPSTEIN (1989), CARPENTER (1983), BOSS (1992), HAIMO (1997), DUDEQUE (2003; 2005).

6 A bem da verdade, a Sonata para Piano op.1, concluida em 1908, poderia receber essa primazia, contudo, a motivação para essa peça teria sido a realização de um exercício (ainda que bastante sofisticado e extremamente bem sucedido) proposto por Schoenberg, de composição de um movimento de sonata com material tonal estendido (HILMAR, 1984, p.18). A construção da Sonata op.1 foi fortemente influenciada pela Sinfonia de Câmara de Schoenberg, cuja composição a antecede em cerca de dois anos. Alguns procedimentos composicionais presentes em ambas as obras, por sua vez, possuem relações estreitas com a estruturação das canções op.2, como será demonstrado.

7 Para comentários sobre alguns princípios teóricos para a Grundgestalt, sintetizados a partir de escritos de Schoenberg e de outros autores, ver EMBRY (2007, p.25-7).

8 GAULDIN (1999, p.37-8) enumera alguns elementos musicais que têm a função de retratar a condição amorosa de Berg na época da composição do op. 2. Em resumo: (a) a tonalidade de Ré-menor, da terceira canção, como a "tonalidade de Helene"; (b) o acrônimo ABH (a sequência de notas Lá-Sib-Si, na notação alemã) representando o casal (Alban Berg e $\underline{H}$ elene); (c) citações em alturas originais de gestos melódicos e harmônicos do Prelúdio de Tristão e Isolda. Além destas, este estudo leva em consideração outras referências extramusicais como motivadoras para a formação da Grundgestalt composta do ciclo, como será visto a seguir.

9 Para os diversos pontos de contato existentes entre a Sinfonia de Schoenberg e a Sonata de Berg, ver ALMADA (2008) e ALMADA (2011b).

10 É aqui adotada a notação proposta por BOSS (1992).

11 Para uma tipologia provisória das operações de variação progressiva, ver ALMADA (2011b, p.19).

12 Como já comentado, a consideração desses elementos como uma das fontes de material para a Grundgestalt do op.2 é baseada em informações apresentadas por GAULDIN (1999).

13 Ver ALMADA (2011b). Seria possivel também relacionar a GG S à Célula Básica I proposta por JARMAN (1997), como um dos elementos mais recorrentes na música de Berg. Trata-se do tetracorde (0167), que pode ser formado pela adição de dois tritonos separados por intervalo de segunda menor ou pela superposição de dois tricordes (016) que contenham duas classes de altura em comum.

14 A letra "S" correponde a Mi bemol na notação alemã. Esse conjunto específico é considerado o "monograma" de Schoenberg (STUCKENSCHMIDT, 1991, p.446), sendo bastante recorrente tanto em sua música como uma espécie de assinatura, quanto na de seus amigos/discípulos Berg e Webern, com o propósito de homenagem.

150 texto da canção é o seguinte: "Schlafend trägt man mich / in mein Heimatland. / Ferne komm'ïch her, / über Gipfel, über Schlünde, / über ein dunkles Meer/ in mein Heimatland". Uma possivel tradução: "Dormindo, sou levado de volta / à minha pátria / Venho de longe, / por sobre picos e desfiladeiros, / por sobre um mar profundo, / à minha pátria".

16 A partitura do ciclo op.2 (Berlim: Schlesinger, 1928) está disponivel no seguinte site: http://216.129.110.22/files/imglnks/usimg/3/30/IMSLP22900PMLP52400-Berg__4_Lieder_Op._2.pdf

17 Tal tipo de estratégia (ligada ao que se costuma designar como neo-schenkerianismo) vem sendo bastante empregada em análises estruturais de peças do repertório tonal expandido ou mesmo pós-tonal, desde a iniciativa pioneira de SALZER (1952). Evidentemente, nesse tipo de análise não se busca uma correspondência entre os eventos analisados e uma estrutura primordial (Ursatz) estipulada a priori, mas tão-somente evidenciar relações de prolongação e/ou de coerência entre elementos presentes em diferentes estratos hierarquizados de significação musical. Registre-se que três dos estudos referenciais para este trabalho adotam estratégias semelhantes para analisar relações estruturais: AYREY (1982), JARMAN (1987) e GAULDIN (1999). Acrescente-se ainda que, com o objetivo de facilitar a observação das relações derivativas, as reduções serão quase sempre apresentadas sem armaduras de clave.

18 Ressalte-se que esse trecho constitui apenas um breve recorte de uma passagem de maior extensão e densidade e que, em nome da clareza, dobramentos e algumas linhas subordinadas às principais foram omitidas do exemplo.

19 Ambos os conceitos, emprestados da terminologia da Genética, originam-se de uma análise derivativa dos temas principais da Sinfonia de Câmara de Schoenberg, a partir de suas relações com a Grundgestalt da obra (ALMADA, 2011a). Entenda-se forma fenotípica neste contexto como aquela que, embora não seja derivada por abstração de elementos da ideia primordial, resulta da concretização de um deles (ou da combinação de vários), tornando-se assim um fenômeno da superfície musical. Isso não significa que relações "ocultas", mais profundas (ou mesmo indiretas) entre fenótipo e genótipo possam existir, como é o presente caso, aliás. Os elementos fenotípicos podem, por sua vez, constituir bases para desdobramentos subsequentes, através de variação progressiva, incluindo combinações com formas genotípicas.

20 GAULDIN (1999, p.38-9) também atribui a esse motivo (e a todas as suas subsequentes reaparições na canção) uma clara referência ao gesto inicial de Tristão e Isolda.

21 Fato que também não passa despercebido a PERLE (1977), JARMAN (1997) e STRAUS (2005). Como comenta este último, a simetria interna do acorde de "sexta francesa" faz com que existam para ele apenas seis transposições distintas, todas elas presentes nesse trecho inicial da peça (p.126), o que sugere não apenas que Berg estaria plenamente consciente dessa propriedade harmônica, como a teria empregado engenhosamente como recurso a favor da expressão de seu tonalismo expandido.

22 Por questões de clareza as formas tricordais derivadas de $\mathrm{S}$ por transposição e/ou inversão que se apresentam em diversas superposições são indicadas no Ex.8 através de linhas que conectam as notas envolvidas.

23 Neste caso, demarcando nitidamente o fechamento de uma transição entre duas seções estruturalmente mais relevantes (1 e 3 ). Para a definição do procedimento estruturador de liquidação, ver SCHOENBERG (1990, p.58-9). 
24 Registre-se que o acorde é apresentado de início em modo maior (como um dominante para o IV grau, que, no entanto, não se Ihe sucede), prolongando a verdadeira resolução subsequente (o acorde de Mib menor), como se vê no Ex.10.

25 Observe-se especialmente a relação entre o terceiro e o quarto versos, em sequência por segunda menor descendente. Como afirma JAMEUX (1980, p.52), a topografia da linha melódica nesse ponto parece fazer "figuralismo musical", descrevendo as textuais viagens sobre picos e desfiladeiros.

26 AYREY (1982, p.192-3) considera ambos os trechos "Heimatland" (c.1-4 e c.15-18) associados ao ambiente dominante/"sexta francesa", tendo a estabilidade tônica (o acorde de Mib maior dos c.8-9) relação com o termo "ferne" ("longe"), numa inversão de papéis conceituais em relação às metáforas convencionais sobre o funcionalismo tonal. Ainda que instigante, tal interpretação perde força ao não levar também em conta o claro apoio sobre Mib que finaliza a canção (c.17-8), que representaria, enfim, a concretização do retorno esperado.

27 Que é também, como o V grau prolongado, um acorde de "sexta francesa" (o Lá da melodia corresponde à quinta diminuta do acorde, enarmonicamente). Aqui surge uma possivel "explicação" para o uso da terça maior, já que esse acorde pode ser reinterpretado como o V grau da canção seguinte, ambientada em Láb-menor.

28 Comparar com o Ex.2 de AYREY (1982, p.192) que, no entanto, dá conta apenas da relação entre as duas canções iniciais. 0 mesmo autor também examina todo op.2/II a partir de uma adaptação metodológica da análise schenkeriana (com objetivos e resultados distintos em relação à presente interpretação). Para uma comparação, ver AYREY (1982, p.198-9).

29 São estas as três canções tonais do ciclo (ainda que numa acepção bastante expandida), com armaduras de clave, o que possui implicações estruturais, como é demonstrado a seguir. A quarta canção, Warm die Lüfte, tem a primazia de ser a primeira peça atonal de Berg e merecerá uma atenção especial numa análise futura.

30 Fato que é também destacado por GAULDIN (1999, p.36).

31 Embora as realizações da assim chamada Segunda Escola de Viena possam ser consideradas o apogeu da aplicação da teoria da Grundgestalt, observam-se reverberações de sua influência em obras de compositores mais recentes, como Stockhausen, cuja técnica construtiva denominada Formula pode ser vista como uma reelaboração daquele conceito schoenberguiano.

32 Isso estreita ainda mais as ligações entre o op.2 e a Sinfonia, já que esta obra schoenberguiana representa um ponto de aperfeiçoamento ótimo no que se refere à concisão formal da estrutura de sonata, numa linha que remonta ao sexteto Noite Transfigurada op.4, de 1899. Para uma discussão mais detalhada sobre a busca de Schoenberg pela concisão formal em suas obras tonais, ver ALMADA (2007, p.21-30 e p.41-45).

Carlos Almada é Professor Adjunto da Escola de Música da UFRJ, atuando como docente nos níveis de graduação e pós-graduação. É doutor e mestre em Música pela UNIRIO, ambos os cursos com pesquisas voltadas para análises estruturais da Primeira Sinfonia de Câmara op.9, de Arnold Schoenberg. É compositor, com diversas obras apresentadas em edições da Bienal de Música Brasileira Contemporânea, bem como registradas em CDs pela gravadora Ethos Brasil. Atua também na música popular como arranjador, com inúmeros trabalhos gravados recentemente. É pesquisador com vários artigos publicados em periódicos acadêmicos, tendo apresentado comunicações nos quatro últimos congressos da ANPPOM, a partir de suas pesquisas. É autor dos livros Arranjo (Editora da Unicamp, 2001), A estrutura do choro (Da Fonseca, 2006) e Harmonia funcional (Editora da Unicamp, 2009), bem como coautor de uma série de 12 livros sobre música popular brasileira, publicados entre 1998 e 2010 pela editora americana MelBay. 